\title{
UMA PROPOSTA PARA GESTÃO DOS RESÍDUOS SÓLIDOS DA SAÚDE: UM ESTUDO DE CASO NO CURSO TÉCNICO DE ENFERMAGEM DE UMA INSTITUIÇÃO PÚBLICA FEDERAL
}

Rosângela dos Santos Nascimento Mestre em Sistema de Gestão pela Universidade Federal Fluminense (UFF), Niterói, RJ, Brasil rosangelamartes@gmail.com

Augusto da Cunha Reis

Doutor em Engenharia de Produção pela Pontifícia Universidade

Católica do Rio de Janeiro (PUC), Rio de janeiro, RJ, Brasil augusto.reis@cefet-rj.br

\section{RESUMO}

Este artigo aborda a questão dos problemas gerados pela produção de resíduos de serviço de saúde em um laboratório de Curso Técnico de Enfermagem de uma Instituição Pública Federal. Este trabalho objetiva mapear os principais riscos à saúde dos discentes, docentes ao manipularem os resíduos gerados durante as atividades práticas no laboratório e ao profissional da limpeza, durante a higienização do laboratório após as aulas práticas. A metodologia da pesquisa quanto à abordagem é qualitativa e quantitativa; aos meios, bibliográfica, estudo de caso e surveys; aos fins, descritiva e aplicada. Em relação aos resultados, constatou-se problemas para descarte dos resíduos infectantes e químicos, e falta de um local apropriado para acondicionamento temporário dos resíduos até o descarte final. Averiguou-se a carência de empresas para a realização de descarte dos resíduos de serviço de saúde produzidos nas aulas práticas de laboratório. Elencam-se na conclusão, procedimentos que determinem regras básicas a serem adotadas na implementação de uma proposta de gerenciamento do processo de resíduos do laboratório do Curso Técnico de Enfermagem.

Palavras-chave: Resíduos de saúde. Descarte. Acondicionamento. Gerenciamento.

\section{A PROPOSAL FOR THE MANAGEMENT OF SOLID HEALTH WASTE: A CASE STUDY IN THE TECHNICAL NURSING COURSE OF A FEDERAL PUBLIC INSTITUTION}

\begin{abstract}
This article addresses the issue of problems generated by the production of health service waste in a laboratory of the Technical Nursing Course of a Federal Public Institution. This work aims to map the main risks to the health of students, teachers when handling the waste generated during practical activities in the laboratory and the cleaning professional, during the cleaning of the laboratory after practical classes. The research methodology regarding the approach is qualitative and quantitative; to the media, bibliography, case study and survey; purposes, descriptive and applied. Regarding the results, there were
\end{abstract}


problems with the disposal of infectious and chemical residues, and the lack of an appropriate place for the temporary storage of residues until final disposal. There was a lack of companies to dispose of waste from the local health service in practical laboratory classes. They are listed at the conclusion of the procedures, which determine basic rules to be adopted in the implementation of a proposal for the management of the waste process in the laboratory of the Technical Nursing Course.

Keywords: Health waste. Discard. Packaging. Management. 


\section{INTRODUÇÃO}

Atualmente as instituições de ensino têm dificuldade em gerenciar os resíduos produzidos em seus laboratórios (PENATTI; GUIMARÃES; SILVA, 2008). Muitos são os fatores responsáveis pelo problema dos resíduos gerados como: falta de monitoramento, capacitação de funcionários que vão lidar diretamente com os resíduos, falta de empresas para coletar esses resíduos. Cabe salientar, que estes locais são apenas formas de confinamento sem qualquer estrutura para tal finalidade, podendo ocasionar graves consequências para o meio ambiente.

Segundo Gomes e Esteves (2012), devido as suas características tóxicas e patogênicas, os resíduos de serviço de saúde representam um dos grandes problemas para o meio ambiente e sociedade. Complementa os autores, que o crescimento da preocupação mundial com o tema abordado levou as nações a reverem suas legislações, tornando-as mais restritivas (GOMES; ESTEVES, 2012). Toda a atenção está voltada em torno dos geradores, que a partir de agora serão responsabilizados pelos resíduos que produzem, sendo forçados a destiná-los de forma adequada (JARDIM, 1998).

O manejo seguro e tratamento são atualmente importantes para os resíduos hospitalares, pois são potencialmente infectantes e perigosos (BRASIL, 2001). Por meio de práticas corretas de gerenciamento, é possível prevenir e minimizar os efeitos negativos dos Resíduos de Serviços de Saúde (RSS) ao meio ambiente e à saúde humana, bem como medidas de preservação ambiental. (SEVERO et al., 2012).

Vários segmentos da sociedade vêm se preocupando com a questão ambiental, as instituições de ensino não podem ignorar o fato de que são fontes geradoras de resíduos biológicos e químicos, e responsáveis por causar impactos ao meio ambiente, além de problemas de saúde da população.

De acordo com os autores Ventura, Reis e Takayanagui (2010), os resíduos de serviços de saúde (RSS), quando gerenciados inadequadamente pelos estabelecimentos geradores, oferecem risco potencial ao ambiente e à vida de forma geral, devido às características biológicas, químicas e físicas que lhes são inerentes. Por isso, há necessidade de um gerenciamento adequado dos resíduos produzidos no laboratório da instituição onde a pesquisa foi aplicada, através do monitoramento dos procedimentos que oferecem riscos para os alunos, professores e aos profissionais da limpeza. 
Sendo assim, o presente artigo objetiva apresentar uma proposta de melhoria no gerenciamento dos resíduos de serviço de saúde do laboratório do Curso Técnico de Enfermagem.

\section{REVISÃO DA LITERATURA}

Este capítulo foi definido a partir da análise dos principais assuntos relacionados ao tema da pesquisa. Para melhor esclarecimento, os aspectos teóricos foram divididos em 04 (quatro) seções, onde foram abordados assuntos relacionados com a Classificação dos Resíduos de Saúde, Gerenciamento dos Resíduos de Saúde, Riscos à Saúde Humana dos RSS, Impactos dos Resíduos de Saúde ao Meio Ambiente, nesta ordem.

\subsection{Classificação dos resíduos de saúde}

No Brasil, há várias classificações de resíduos, sendo as mais conhecidas a da Associação Brasileira de Normas Técnicas (ABNT), do Conselho Nacional do Meio Ambiente (CONAMA) e da Agência de Vigilância Sanitária (ANVISA).

A classificação dos resíduos sólidos de saúde em cinco grupos a saber A, B,C, D e E, foi estabelecida pela Resolução RDC n 306/2004 (ANVISA, 2004) e Resolução no 358 /2005 (CONAMA, 2005).

De acordo com a Norma ABNT (2004), os resíduos são classificados quanto aos seus riscos potenciais ao meio ambiente e à saúde pública, para que se viabilize seu gerenciamento adequado.

De acordo com a Resolução da Diretoria Colegiada - RDC no 306/04 (ANVISA, 2004) os resíduos são divididos da seguinte forma:

Grupo A - todos os resíduos que contenham presença de agentes biológicos e que por suas características, podem oferecer risco de contaminação.

Grupo B - se encaixam nesse grupo todos os resíduos que contém substâncias químicas que podem expor risco à saúde pública ou ao meio ambiente, dependendo de suas características de inflamabilidade, corrosividade, reatividade e toxicidade. 
Grupo C - materiais sucedidos de atividades humanas que estejam contaminados por radionuclídeos que esteja presente em grandes quantidades especificadas pelo Conselho Nacional de Energia Nuclear (CNEN).

Grupo D - pertencem a esse grupo todos os resíduos que não ofereçam risco biológico, químico ou radiológico à saúde ou ao meio ambiente

Grupo E - esse grupo contém todos os materiais perfurocortantes ou escarificantes.

A classificação adotada pela ABNT, através da NBR 12.807 (ABNT, 2013), que trata da terminologia do RSS, divide os resíduos em três classes: Classe A - Infectantes; Classe B Especiais (radiativos, farmacêuticos e químicos) e Classe C - Comuns.

Esses resíduos gerados fazem parte das etapas de atendimento, diagnóstico e tratamento de pacientes em veterinárias, clínicas médicas, odontológicas, laboratórios, drogarias, centros de pesquisas (ABNT, 2013).

\subsection{Gerenciamento dos resíduos de saúde}

Segundo Oliveira et al. (2014), na atualidade constitui-se um grande problema tanto para países ricos quanto para países pobres, proporcionar uma solução segura e eficiente para os RSS. Os autores complementam que não existe um consenso, nem uma fundamentação científica, que permitam garantir um método mais eficiente de tratamento e destinação final, sem que ocorra danos à saúde humana e ao meio ambiente (OLIVEIRA et al., 2014).

Para Marinkovic et al. (2008), é dada prioridade à redução das quantidades e do potencial de danos. Onde isso não é possível, a gestão inclui redução por triagem e separação, pré-tratamento no local, transporte seguro, tratamento final e disposição sanitária.

Os métodos preferidos devem ser os menos nocivos para a saúde humana e para o meio ambiente. O gerenciamento integrado de resíduos médicos poderia reduzir consideravelmente as quantidades e consequentemente as tensões financeiras.

Em 2003, a RDC no 33/2003 (ANVISA, 2003) criou um regulamento técnico para o gerenciamento de RSS e, logo depois, a RDC no 306/2004 (ANVISA, 2004) apresentou uma revisão e atualização desse regulamento. 
De acordo com a ANVISA (2006), na gestão de resíduos sólidos de serviços de saúde, os estabelecimentos prestadores de serviços de saúde podem contratar outros prestadores para realizar os serviços de limpeza, coleta de resíduos, tratamento, disposição final e comercialização de materiais recicláveis. Por isso, é importante ter à disposição mecanismos que permitam verificar se os procedimentos definidos e a conduta dos atores estão em sincronia com as leis. As contratações devem exigir e garantir que as empresas cumpram as legislações vigentes.

Atualmente, tanto para a ANVISA como para o CONAMA, os geradores de RSS são obrigados a elaborar e implantar o Plano de Gerenciamento de Resíduos de Serviços de Saúde (PGRSS) específico conforme as características de cada unidade geradora.

De acordo com a ANVISA, o PGRSS constitui-se em:

O documento que aponta e descreve as ações relativas ao manejo dos resíduos sólidos, observadas suas características e riscos no âmbito dos estabelecimentos, contemplando os aspectos referentes à geração, segregação, acondicionamento, coleta, armazenamento, transporte, tratamento e disposição final, bem como as ações de proteção á saúde pública e ao meio ambiente. (ANVISA, 2004).

De acordo com o CONAMA, o PGRSS constitui-se em:

O documento integrante do processo de licenciamento ambiental baseado nos princípios da não geração de resíduos e na minimização da geração de resíduos, que aponta e descreve as ações relativas ao seu manejo, contemplando os aspectos referentes à geração, segregação, acondicionamento, coleta, armazenamento, transporte, reciclagem, tratamento e disposição final, bem como a proteção à saúde pública e ao meio ambiente. (CONAMA, 2005).

\subsection{Riscos à saúde humana dos RSS}

Os agentes físicos, químicos e biológicos são capazes de causar danos à saúde do trabalhador, em função de sua natureza, concentração, intensidade e tempo de exposição sendo assim, considerados riscos ao ambiente de trabalho (MINISTÉRIO DO TRABALHO E EMPREGO, 2005).

Segundo a Norma regulamentadora 32 - NR 32. Consideram-se Agentes Biológicos os micro-organismos geneticamente modificados ou não, as culturas de células, os parasitas; as toxinas e os príons (MINISTÉRIO DO TRABALHO E EMPREGO, 2005).

Sabe-se que os riscos biológicos representam uma preocupação para os indivíduos que os manipulam, mas os produtos químicos e farmacêuticas utilizadas em 
estabelecimentos de saúde são classificados como perigosos, como é o caso de substâncias tóxicas, genotóxicas, corrosivas, inflamáveis, reativas e explosivas (BRASIL, 2010).

Segundo Moreschi et al. (2014) os estudos evidenciam a necessidade de capacitar os profissionais que trabalham em locais onde são produzidos resíduos de saúde, para o correto gerenciamento dos resíduos, visto que uma parcela de profissionais não sabe o que são resíduos, tampouco atribuem importância ao correto manuseio destes nas práticas de saúde. Reconhecem, que existe negligência nos procedimentos realizados que geram impacto ambiental e suas repercussões para a comunidade.

De acordo com a Resolução ANVISA RDC no 306/2004 (ANVISA, 2004), a capacitação deve abordar a importância da utilização correta de equipamentos de proteção individual uniforme, luvas, avental impermeável, máscara, botas e óculos de segurança específicos a cada atividade, bem como a necessidade de mantê-los em perfeita higiene e estado de conservação.

\subsection{Impactos dos resíduos de saúde ao meio ambiente}

De acordo com o Ministério da Saúde, a Saúde Ambiental juntamente com a Saúde Pública representa grandes desafios atuais, em estruturar sistemas de monitoramento e vigilância, de forma a prevenir, monitorar mudanças ocorridas no meio ambiente (ANVISA, 2006). Evitando assim maiores consequências a saúde humana.

Assim, os esforços para a construção de indicadores que apontem para as interrelações de mudanças ambientais e situação de saúde se encontram na origem do processo de institucionalização da vigilância em saúde ambiental no âmbito do Setor Saúde na passagem do século XX para o XXI, inicialmente pelo Decreto no 3.450/2000 da Presidência da República, estabelecendo no antigo Centro Nacional de Epidemiologia - CENEPI.

Segundo Oliveira et al. (2014), para a promoção de saúde, qualidade de vida e preservação do meio ambiente é necessário um adequado gerenciamento dos resíduos gerados pelos estabelecimentos de saúde. Para isso, faz necessário que os gestores municipais, estaduais e federais conheçam, o assunto profundamente e coloquem todas as normas vigentes e legislação em prática.

De acordo com Alvarenga e Nicoletti (2010), a contaminação atmosférica, do solo e dos recursos hídricos em todo o mundo, surgiram a partir de um crescimento demográfico e 
a expansão industrial. Já há uma conscientização quanto à deterioração do meio ambiente e à urgência de se mudar ou, ao menos, diminuir esse processo. Um dos problemas atuais está relacionado ao descarte de medicamentos e seu impacto ao ambiente decorrente de uma contaminação do meio ambiente. O Brasil é um dos maiores consumidores de medicamentos, o aumento do consumo trará como consequência, maior quantidade de sobras de medicamentos e embalagens que terão como destino o lixo comum. (ALVARENGA; NICOLETI, 2010).

A Política Nacional de Educação Ambiental, Lei no 9.795 (BRASIL, 1999), dispõe sobre a educação ambiental e a conservação do meio ambiente e a Política Nacional de Recursos Hídricos, Lei no 9.433 (BRASIL, 1997), tem como objetivo assegurar a disponibilidade da água em padrões de qualidade.

De acordo com a Resolução CONAMA no 358 (CONAMA, 2005), e na RDC no 306 (ANVISA, 2004), o gerenciamento fundamentado nessas Resoluções, deve caber a cada estabelecimento de saúde gerenciar desde a geração até sua disposição final. Salienta-se aqui que os medicamentos são classificados como resíduos do grupo B, cujas substâncias químicas poderão apresentar risco à saúde humana ou ao meio ambiente, dependendo de suas características.

Segundo Gonçalves et al. (2011), é necessário a conscientização acerca da geração, do processamento e do descarte de resíduos do grupo B que levam a poluição de solos e águas, por formas hidrossolúveis, contendo resíduos tóxicos, metais pesados, compostos cancerígenos.

Cabe destacar que os resíduos do grupo B são identificados pelo símbolo de risco associado, de acordo com a NBR 7.500 (ABNT, 2011) e com a discriminação de substância química e frases de risco. O armazenamento de resíduos químicos deve atender à NBR 12.235. (ABNT, 1992).

De acordo com a Resolução CONAMA no 358 (CONAMA, 2005), estação de transferência de resíduos de serviços de saúde: é uma unidade com instalações exclusivas, com licença ambiental expedida pelo órgão competente, para executar transferência de resíduos gerados nos serviços de saúde, garantindo as características originais de acondicionamento, sem abrir ou transferir conteúdo de uma embalagem para a outra.

De acordo com Nascimento et al. (2009), os resíduos de serviços de saúde geram polêmicas quanto a importância para a saúde humana, animal e ambiental. Em um aterro 
sanitário avaliou-se uma grande quantidade de resíduos de serviço de saúde a ocorrência de bactérias de natureza relevantes e de seu perfil de susceptibilidade aos antimicrobianos. Foram processadas para isolamento seletivos em alíquotas de chorume, a bactéria Staphylococcus sp, bastonetes Gram negativos da família Enterobacteriaceae não fermentadores. Foi observada resistência bacteriana a todos os antimicrobianos testados, além de resistência a mais de uma droga. Estes resultados encontrados nos resíduos de serviço de saúde, permitem sugerir que bactérias viáveis representam riscos à saúde humana e animal. Além do que, a existência de bactérias de linhagens multirresistentes reforça a hipótese de os resíduos de serviços de saúde agirem como reservatórios de marcadores de resistência, com impacto ambiental. Os riscos de transmissão de doenças infecciosas associadas a micro-organismos multirresistentes, é devido à falta de legislação regional de segregação, tratamento e destino de resíduos.

\section{MÉTODO}

Optou-se neste estudo, usar elementos de abordagens de pesquisa qualitativa e quantitativa em um modo complementar. Esta abordagem mista permite que o estudo beneficie dos pontos fortes de ambas as abordagens durante a coleta, processamento e análise de dados. De fato, em alguns casos, as fraquezas de um são compensadas pelos pontos fortes do outro. A respeito disso, Flick (2004) apontou que "o uso de mais de uma abordagem na coleta de dados e análise abre várias perspectivas para promover a qualidade na pesquisa".

Caracteriza-se assim, como descritivo, exploratório de abordagem quali-quanti. Foi realizada uma pesquisa bibliográfica e descritiva, buscando à contextualização, o levantamento do panorama da atual situação em relação aos RSS, onde foi feito uma análise na legislação e o uso das tecnologias de tratamento de resíduos de serviço de saúde existentes, além de compreender os problemas da geração dos resíduos de serviço de saúde, reflexos na saúde da população e do meio ambiente e discussões sobre periculosidade desta parcela de resíduos. Deste modo, foram obtidos os dados básicos para caracterização, análise e estudo do problema.

A pesquisa bibliográfica ocorrerá no início do processo da pesquisa de investigação e o pesquisador assume uma postura reflexiva, diferente do estudo quantitativo, o qual o 
papel do pesquisador deve manter a objetividade e o distanciamento do processo de pesquisa.

A técnica adotada nesta pesquisa é o estudo de caso, visto que os estudos de caso representam a estratégia adequada quando se deseja responder questões do tipo "como" e "por que", quando o pesquisador tem pouco controle sobre os acontecimentos e quando o foco se encontra em fenômenos contemporâneos inseridos em algum contexto da vida real.

Segundo Gil (2009), os estudos de caso requerem a utilização de múltiplas técnicas de coleta de dados para garantir a profundidade necessária ao estudo e a inserção do caso em seu contexto, conferindo assim, maior credibilidade aos resultados.

De acordo com Lakatos e Marconi (2010) são vários os procedimentos para a realização da coleta de dados, que variam de acordo com as circunstâncias ou com o tipo de investigação. A escolha do instrumento de pesquisa deve ser de acordo com os métodos de pesquisa utilizados, no caso desta pesquisa, estudo de caso e surveys. Segundo Gil (2009), nos surveys o questionário e a entrevista são as melhores opções; já nos estudos de caso, a entrevista e a observação, são utilizadas frequentemente. Complementa Gil (2009), a utilização do estudo de caso é mais adequada para estudos exploratórios e descritivos.

Foram realizadas as elaborações e aplicações de questionários, para o professor responsável pelo laboratório do Curso Técnico de Enfermagem, aos discentes e ao profissional de higiene.

O instrumento aplicado ao profissional da limpeza foi um questionário com perguntas fechadas com informações acerca da idade, escolaridade, ocorrência de acidentes com material perfurocortante e o uso de EPIs.

O instrumento aplicado para os 68 discentes das três séries do Curso Técnico de Enfermagem, foi um questionário com 09 perguntas fechadas. Os conteúdos versaram sobre os aspectos de biossegurança, descarte de resíduos, conscientização a respeito da disposição final dos RSS. Na construção do questionário, foi utilizada a escala Likert, graduando-se as respostas de 1 a 4, seguindo um grau de concordância. Esse grau foi distribuído conforme as definições: 1- Nunca (N) / 2- Raramente (R) / 3- Quase sempre (QS) /4 - Sempre (S).

Para o responsável pelo gerenciamento dos resíduos de serviço de saúde, o instrumento aplicado foi um questionário com perguntas abertas, com informações acerca dos aspectos organizacionais do gerenciamento dos RSS, Perspectivas Técnico-Operacionais e manejo dos resíduos do grupo A e E. 
Foi feita uma pesquisa de campo no Laboratório de Enfermagem, onde foram fotografados os locais de descarte de resíduos perfurocortantes, infectantes e resíduos comuns. No segundo dia da pesquisa foi fotografado o local onde as caixas com perfurocortantes e o lixo infectante são armazenados temporariamente.

\section{RESULTADO E DISCUSSÃO}

Considerando o levantamento e análise dos dados, em consonância com a literatura estudada, apresentam-se no quadro 01, quadro 02 e quadro 03, o diagnóstico do gerenciamento dos resíduos produzidos no Laboratório do Curso de Enfermagem da situação da instituição pública federal de ensino.

Mediante as respostas dos questionários, depoimentos dos sujeitos e das observações realizadas no laboratório do curso Técnico de Enfermagem foram lidos e analisados em relação à adequação com o tema; as respostas foram analisadas e possibilitaram selecionar as informações mais significantes. Foram elencados problemas com relação: sinalização, identificação, acondicionamento, armazenamento temporário, coleta dos RSS produzidos no laboratório.

Diante das respostas obtidas dos questionários aplicados aos discentes, e das visitas realizadas no laboratório observou-se, precária sinalização e identificação dos recipientes utilizados, o que pode acarretar problemas no momento da segregação, provocando misturas de substâncias químicas perigosas para o indivíduo e meio ambiente.

Os resíduos infectantes, "quase sempre" ou "sempre" são acondicionados em sacos pretos, e nunca são descartados em sacos de cor branca leitosa.

De acordo com a RDC no 306/04 (ANVISA, 2004), a identificação é uma maneira de permitir e facilitar o reconhecimento dos resíduos contidos nos sacos ou nos recipientes através das informações contidas nos mesmos, contribuindo dessa forma para um manejo seguro.

Durante as visitas ao laboratório, não foram observadas lixeiras para resíduos infectantes, com tampa e pedal, contendo sacos brancos devidamente identificadas. De acordo com a RDC no 306/2004 (ANVISA, 2004).

Também foi informado pelos discentes problemas relacionados ao descarte de resíduos químicos que responderam que "quase sempre" e "sempre", descartam 
substâncias químicas diretamente na pia do laboratório. O problema que ao serem descartadas diretamente na pia do laboratório podem apresentar risco a saúde pública e ao meio ambiente, podendo intoxicar ou provocar lesões ao indivíduo que estiver manuseando.

Observou-se durante a visita ao laboratório que as caixas com materiais perfurocortantes são armazenadas temporariamente na sala de materiais anexa ao laboratório até a coleta, esta sala de materiais, é a mesma que contém equipamentos utilizados nas aulas práticas de Enfermagem. As caixas de papelão utilizadas para descartar resíduos perfurocortantes estão armazenadas em uma sala que não é própria somente para isso, podendo provocar lesões e contaminação ao funcionário da limpeza e alunos caso precisem ter acesso ao ambiente. Essas ficam armazenadas junto com os materiais (fig. 2) em bancada próxima a pia (fig.1). Há o risco dessas caixas tombarem provocando acidente com resíduos perfurocortantes. E estando localizadas próximas a pia de molharem, o que pode comprometer a resistência do material, provocando vazamento ou ruptura e causarem acidente.

De acordo com o relato da gestora responsável pelo laboratório, até o momento da realização desta pesquisa não existia a contratação do serviço para coleta de resíduos de serviço de saúde. A falta de uma empresa para descartar os resíduos de serviços de saúde gera um problema para muitos gestores. O acúmulo de resíduos em um local improvisado pode provocar acidentes, caso um aluno ou funcionário tenham acesso e aparecimento de vetores de doenças.

O acondicionamento consiste no ato de embalar os resíduos segregados, em sacos ou recipientes que evitem vazamentos e resistam às ações de punctura e ruptura. Como a segregação é uma etapa importante no gerenciamento, "consiste na separação de resíduos no momento e local de sua geração, de acordo com as características físicos, químicos e biológicas ou seu estado físico e os riscos envolvidos". RDC no 306/204, constatou-se que os resíduos infectantes são descartados em lixeiras sem tampa e em sacos de lixo preto para descarte de lixo comum.

A falta deste procedimento aumenta os riscos para a saúde dos funcionários e alunos, além de aumentar a quantidade de resíduos infectantes, e impossibilita a reciclagem de resíduos inertes. Com a implantação de um PGRSS, alguns problemas que hoje são observados serão resolvidos, como: redução de resíduos infectantes, falta de tratamento 
para esse tipo de resíduo, redução de riscos à saúde. É necessário construir um modelo de gerenciamento proposto pela legislação.

Para minimizar a quantidade de resíduos infectantes, é necessário orientar os alunos a utilizarem somente lixeiras específicas para descarte de resíduos infectantes. Utilizar manuais com informações sobre forma correta de acondicionamento proposto pela legislação. Como sugestão, utilizar o Manual da ANVISA durante as aulas práticas.

Com relação à geração de resíduos químicos utilizados no laboratório de Enfermagem, constatou-se de acordo com informações obtidas nos questionários aplicados aos alunos, que os resíduos químicos utilizados durante as aulas práticas são descartados na pia do laboratório; o que representa um perigo ao meio ambiente e a saúde pública.

Para evitar esse problema, é necessário orientar aos discentes sobre os problemas ambientais que podem ocorrer quando essas substâncias são descartadas diretamente no esgoto. Como a quantidade de produtos químicos utilizados no laboratório de Enfermagem é pouca, esses resíduos deveriam ter uma etiqueta orientando aos alunos sobre os prejuízos caso esses sejam descartados diretamente no esgoto.

É importante adotar medidas para recuperação ou encaminhar adequadamente todos os resíduos químicos. Além disso, pode ser feita uma lista de produtos químicos que não podem ser descartados diretamente na pia e os problemas ambientais que podem surgir com esse descarte e anexar próximo a pia do laboratório.

Com relação ao funcionário da limpeza a gestora informou que ele não entra em contato com os resíduos produzidos no laboratório. Ao responder o questionário o funcionário da limpeza ratificou que não é autorizado a retirar os RSS, somente os resíduos comuns. Mesmo que o funcionário da limpeza não seja responsável por retirar os resíduos de serviço de saúde produzidos no laboratório, pode ocorrer um acidente, caso ele se encontre em uma situação de risco como: acidentalmente, encontrar uma seringa, algodão contaminados com sangue e secreções.

De acordo com as respostas dos discentes os resíduos infectantes podem ser descartados em sacos de lixo comum, pois não há lixeiras para resíduos infectantes. Segundo a gestora no laboratório só temos distinção entre lixo comum e perfurocortante, e que ainda não há distinção para resíduos infectantes. Observa-se que há uma mistura de resíduos, aumentando os riscos à saúde do funcionário da limpeza. 
Figura 1 - Caixas de papelão estacionadas próximas a pia.

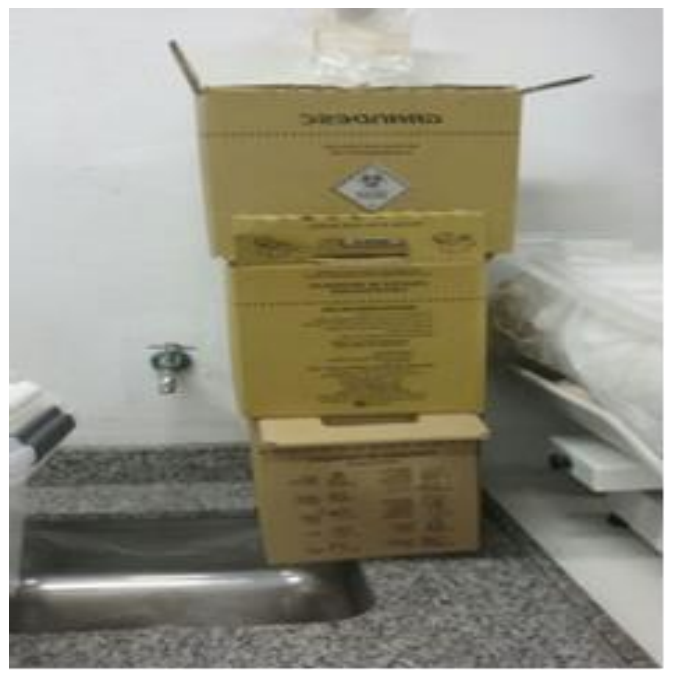

Fonte: Elaborado pela autora (2017).

É importante informar ao profissional da limpeza quanto aos perigos da manipulação desses resíduos, mesmo não sendo autorizado a descartá-los. Treinar o funcionário do laboratório para que identifique e classifique os RSS. A capacitação deve ser realizada de forma continuada e permanente. Orientar os discentes durante as aulas práticas a descartarem somente em lixeiras identificadas para resíduos infectantes. Caso não haja identificação para esse tipo de resíduo, confeccionar etiquetas e anexar nos recipientes. Solicitar a compra de lixeiras para descarte dos resíduos infectantes.

Quanto ao armazenamento temporário dos RSS, por conta do encerramento do contrato com a Empresa que fazia a coleta, hoje armazena-se cada vez mais caixas de perfurocortantes na sala de utilidades em anexo ao laboratório de Enfermagem sem dar o devido tratamento e destino ao resíduo produzido; a sala é pequena sem espaço para armazenar esses resíduos. As caixas ficam empilhadas sobre a bancada, próximas a pia com risco de tombamento (fig.1). E algumas sobre os materiais (fig. 2).

Existe o perigo é desses resíduos com a queda se espalharem e contaminarem o ambiente. Alegou-se que estão armazenadas por falta de um local apropriado e de uma Empresa de coleta. Dependendo do volume de geração e da funcionalidade do estabelecimento, de acordo com a RDC no 306/2004 "poderá ser utilizada a "sala de utilidades" de forma compartilhada. Neste caso, além da área mínima de seis metros quadrados destinados à sala de utilidades, deverá dispor, no mínimo, de mais dois metros quadrados para armazenar dois recipientes coletores para posterior traslado". 
Figura 2 - Caixas de papelão misturadas aos materiais.

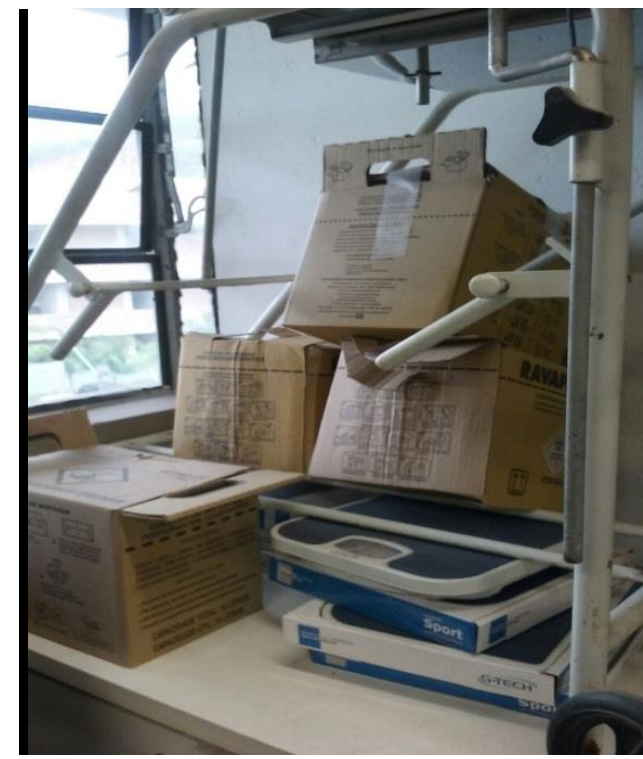

Fonte: Elaborado pela autora (2017).

Para o armazenamento temporário, caso não seja possível um local exclusivo, identificar o local com símbolo correspondente, separá-los evitando misturá-los com equipamentos e outros materiais. Orientar ao funcionário da limpeza a não retirar as caixas de perfurocortantes, caso tenha acesso.

Aquisição de bombonas de plástico para armazenar sacos brancos com identificação com resíduos infectantes ou químicos. As caixas de resíduos podem ficar armazenadas em sacos brancos, importante para evitar que esses resíduos extravasem e contaminem o meio ambiente e o manipulador, e que sejam arrumadas em um local exclusivo, sem misturá-los com outros equipamentos.

Quadro 1 - Apresenta a relação entre os fatores e as respostas das questões aplicadas aos discentes do laboratório do Curso Técnico de Enfermagem.

\begin{tabular}{|c|c|c|}
\hline Questões & Fatores & Respostas \\
\hline 3 & Biossegurança & $\begin{array}{c}\text { "os alunos fazem sempre uso de EPIs durante as aulas práticas de } \\
\text { laboratório" }\end{array}$ \\
\hline $4 ; 5 ; 6$ & Descarte dos RSS & $\begin{array}{l}\text { "os alunos responderam que "quase sempre" e "sempre", } \\
\text { descartam substâncias químicas diretamente na pia do laboratório. }\end{array}$ \\
\hline 6 & Identificação & $\begin{array}{c}\text { "os alunos responderam que "nunca", "raramente", os recipientes } \\
\text { têm identificação. }\end{array}$ \\
\hline
\end{tabular}




\begin{tabular}{|c|c|c|}
\hline $7 . ; 7.2$ & Acondicionamento & $\begin{array}{r}\text { "os alunos responderam que não há lixeiras com tampa e pedal, e o } \\
\text { descarte é feito em lixeiras (sem tampa e pedal), "resíduos } \\
\text { infectantes "quase" e "sempre", são acondicionados em sacos } \\
\text { pretos". }\end{array}$ \\
\hline 8 & $\begin{array}{c}\text { Conscientização a } \\
\text { respeito do destino } \\
\text { dos RSS. }\end{array}$ & "os alunos demonstraram preocupação com o destino final do RSS". \\
\hline 9 & Destino dos RSS & "os alunos do curso de Enfermagens demonstraram preocupação \\
com o destino dos RSS."
\end{tabular}

Fonte: Elaborado pela autora (2017).

Quadro 2 - Apresenta a relação entre os fatores e as respostas das questões aplicadas ao profissional da higiene responsável pela limpeza do laboratório do Curso Técnico de Enfermagem, os fatores e respostas.

\begin{tabular}{|c|c|l|}
\hline Questões & Fatores & \multicolumn{1}{c|}{ Respostas } \\
\hline 6 & Capacitação & "Não passou por treinamento, antes de trabalhar" \\
\hline 7 & Biossegurança & $\begin{array}{l}\text { "O funcionário informou que utiliza os EPIs, mas que não retira esse } \\
\text { tipo de resíduo". }\end{array}$ \\
\hline 8 & Segregação & $\begin{array}{l}\text { "O funcionário da limpeza informou que apenas recolhe o lixo } \\
\text { comum (papel, copos, plásticos etc.) }\end{array}$ \\
\hline 9 & Acondicionamento & $\begin{array}{l}\text { "Recolhe somente o lixo comum produzido no final da aula de } \\
\text { laboratório". }\end{array}$ \\
\hline 10 & Manejo dos resíduos & $\begin{array}{l}\text { "O profissional de higiene não recolhe os resíduos produzidos nas } \\
\text { aulas práticas de laboratório." }\end{array}$ \\
\hline
\end{tabular}

Fonte: Elaborado pela autora (2017).

Quadro 3 - Apresenta a relação entre os fatores e as respostas das questões aplicadas ao gestor responsável pelo laboratório do Curso Técnico de Enfermagem, os fatores e respostas.

\begin{tabular}{|c|c|c|}
\hline Questões & Fatores & Respostas \\
\hline $\begin{array}{l}2,2.1,2.2, \\
2.2 \mathrm{a} 2.3\end{array}$ & $\begin{array}{l}\text { Aspectos organizacionais do } \\
\text { gerenciamento dos RSS. }\end{array}$ & $\begin{array}{l}\text { "De acordo com a gestora falta um plano de } \\
\text { gerenciamento, pois não existe um serviço de coleta } \\
\text { específica para os resíduos produzidos." Não sei ao certo } \\
\text { porque é uma determinação do pessoal terceirizado, e a } \\
\text { coordenação não participa." }\end{array}$ \\
\hline $\begin{array}{c}3.1,3.2, \\
3.3,3.4 \\
3.5,3.5 a \\
3.5 b\end{array}$ & Perspectivas Técnico-operacionais. & $\begin{array}{l}\text { "De acordo com o gestor os profissionais de limpeza não } \\
\text { são autorizados a recolher esse tipo de resíduo." } \\
\text { "Tratando-se do acondicionamento dos resíduos do } \\
\text { grupo A e E, o responsável pelo gerenciamento dos RSS } \\
\text { informou como é realizado o acondicionamento para os } \\
\text { resíduos do grupo E, em caixas de papelão específicas } \\
\text { para material perfurocortante." De acordo com a } \\
\text { gestora: "No laboratório só temos a distinção entre o lixo } \\
\text { comum e perfurocortante. Infelizmente ainda não temos } \\
\text { a distinção para resíduos infectantes. "De acordo com a } \\
\text { gestora, "as caixas com materiais perfurocortante são } \\
\text { armazenadas temporariamente na sala de materiais } \\
\text { anexa ao laboratório até a coleta." "hoje } \\
\text { lamentavelmente, não temos mais este serviço." }\end{array}$ \\
\hline
\end{tabular}




\begin{tabular}{|c|c|c|}
\hline $\begin{array}{c}\text { 4, 4.1, } \\
4.1 .2 \\
4.1 .3,4.1 .4 \\
4.1 .5 \\
4.1 .5 . a \\
4.1 .5 . b \text { e }\end{array}$ & $\begin{array}{c}\text { Manejos dos resíduos do grupo } \mathrm{A} \mathrm{e} \\
\mathrm{E}\end{array}$ & $\begin{array}{l}\text { “O responsável pelo gerenciamento dos RSS informou } \\
\text { que o acondicionamento para os resíduos do grupo E, é } \\
\text { feito em caixas de papelão específicas para material } \\
\text { perfurocortante. "No laboratório só temos a distinção } \\
\text { entre o lixo comum e perfurocortante. Infelizmente } \\
\text { ainda não temos a distinção para resíduos infectantes. }\end{array}$ \\
\hline
\end{tabular}

Fonte: Elaborado pela autora (2017).

Constatou-se durante a realização desta pesquisa a inexistência de um contrato de serviço para coleta externa de resíduos de serviço de saúde e disposição final. O acúmulo de resíduos é perigoso, pois não há tratamento para os resíduos produzidos e um local exclusivo para armazenamento temporário, o que pode comprometer a saúde dos discentes e do funcionário da limpeza, caso ocorra um acidente. A coleta externa consiste na remoção dos RSS do abrigo de resíduos (armazenamento externo) até a unidade de tratamento ou disposição final, pela utilização de técnicas que garantam a preservação das condições de acondicionamento e a integridade dos trabalhadores, da população e do meio ambiente. Deve estar de acordo com as regulamentações do órgão de limpeza pública (ANVISA, 2006). Faz-se necessário tratamento interno dos RSS evitando que cheguem ao destino contaminados e contratar uma Empresa especializada para descartar os RSS.

\section{CONSIDERAÇÕES FINAIS}

O presente estudo se propôs analisar as dificuldades na aplicação da Legislação vigente sobre RSS, a partir de um estudo de Caso no Curso Técnico de Enfermagem de uma Instituição Federal.

É notório que os problemas relacionados, com a geração de resíduos de serviços de saúde e sua disposição final, representa uma grande preocupação para o gestor responsável, preocupado em minimizar a quantidade de resíduos infectantes, para diminuir as consequências que estes podem causar a saúde pública e ao meio ambiente.

Com o levantamento Bibliográfico e o estudo da legislação em vigor, evidenciou aspectos importantes que envolvem os problemas gerados a partir da produção de Resíduos de Saúde no laboratório de Enfermagem. 
É importante pensarmos em oferecer práticas seguras aos nossos alunos e funcionário da limpeza a partir de procedimentos adequados ao descarte e contenção de resíduos de acordo com a legislação em vigor.

Devemos avaliar alguns aspectos atuais como:

*Implantação do plano de gerenciamento

*Capacitação e educação continuada.

* Melhorar a estrutura do laboratório: existência de recursos físicos (instalações e materiais).

Por fim, pretende-se que este estudo possa ser um instrumento que, ao ser aplicado, venha a trazer melhorias ao gerenciamento dos resíduos de serviços de saúde. Além disso, acredita-se que possa servir de base a todas as instituições de ensino com cursos técnicos na área de saúde que buscam solucionar questões similares.

\section{REFERÊNCIAS}

ABNT. NBR 10004: resíduos sólidos - classificação. Rio de Janeiro: ABNT, 2004.

ABNT. NBR 12235: armazenamento de resíduos sólidos perigosos: procedimento. Rio de Janeiro: ABNT, 1992.

ABNT. NBR 12807: resíduos de serviços de saúde: terminologia. Rio de Janeiro: ABNT, 2013.

ABNT. NBR 7500: identificação para o transporte terrestre, manuseio, movimentação e armazenamento de produtos. Rio de Janeiro: ABNT, 2011.

ALVARENGA, L. S. V.; NICOLETTI, M. A. Descarte doméstico de medicamentos e algumas considerações sobre o impacto ambiental decorrente. Revista Saúde, São Paulo, v. 4, n. 3, p. 34-39, 2010.

ANVISA. Manual de gerenciamento de resíduos de serviços de saúde. Brasília, DF: Agência Nacional de Vigilância Sanitária, 2006.

ANVISA. Resolução RDC no 306, de 7 de dezembro de 2004. Dispõe sobre o Regulamento Técnico para o gerenciamento de resíduos de serviços de saúde. Brasília, DF: Agência Nacional de Vigilância Sanitária, 2004.

ANVISA. Resolução RDC no 33, de 25 de fevereiro de 2003. Dispõe sobre o Regulamento Técnico para o gerenciamento de resíduos de serviços de saúde. Brasília, DF: Agência Nacional de Vigilância Sanitária, 2003. 
BRASIL. Lei no 12.305, de 2 de agosto de 2010. Institui a Política Nacional de Resíduos Sólidos; altera a Lei no 9.605, de 12 de fevereiro de 1998; e dá outras providências. Brasília, DF: Presidência da República, 2010. Disponível em:

http://www.planalto.gov.br/ccivil_03/_Ato2007-2010/2010/Lei/L12305.htm. Acesso em: 20 jul. 2019.

BRASIL. Lei no 9.433, de 8 de janeiro de 1997. Institui a Política Nacional de Recursos Hídricos, cria o Sistema Nacional de Gerenciamento de Recursos Hídricos, regulamenta o inciso XIX do art. 21 da Constituição Federal, e altera o art. 10 da Lei no 8.001, de 13 de março de 1990, que modificou a Lei no 7.990, de 28 de dezembro de 1989. Brasília, DF: Presidência da República, 1997.

BRASIL. Lei no 9.795, de 27 de abril de 1999. Dispõe sobre a educação ambiental, institui a Política Nacional de Educação Ambiental e dá outras providências. Brasília, DF: Presidência da República, 1999.

BRASIL. Projeto reforço à reorganização do Sistema Único de Saúde (REFORSUS): gerenciamento de resíduos de serviços de saúde. Brasília, DF: Ministério da Saúde, 2001.

CONAMA. Resolução CONAMA no 358, de 29 de abril de 2005. Dispõe sobre o tratamento e a disposição final dos resíduos dos serviços de saúde e dá outras providências. Diário Oficial da União: seção 1, Brasília, DF, n. 84, p. 63-65, 4 maio 2005.

FLICK, Uwe. Uma introdução à pesquisa qualitativa. Porto Alegre: Bookman, 2004.

GIL, A. C. Como elaborar projetos de pesquisa. 4. ed. São Paulo: Atlas, 2009.

GOMES, Luciana Paulo; ESTEVES, Roger Vinicius Rosa. Análise do sistema de gerenciamento dos resíduos de serviços de saúde nos municípios da bacia hidrográfica do Rio dos Sinos, Rio Grande do Sul, Brasil. Engenharia Sanitária e Ambiental, Rio de Janeiro, v. 17, n. 4, p. 377384, out./dez. 2012. Disponível em: https://www.scielo.br/pdf/esa/v17n4/v17n4a04. Acesso em: 10 abr. 2015.

GONÇALVES, E. N. M.; SANTOS, C. B.; BADARÓ, M. L. de S.; FARIA, V. A.; RODRIGUES, E.; MENDES, M. E.; SUMITA, N. M. Modelo de implantação de plano de gerenciamento de resíduos clínicos. Jornal Brasileiro de Patologia e Medicina Laboratorial, [S. I.], v. 47, n. 3, p. 249-255, 2011.

JARDIM, W. F. Gerenciamento de resíduos químico em laboratórios de ensino e pesquisa. Revista Química Nova, São Paulo, v. 21, n. 5, p. 671-673, 1998.

LAKATOS, Eva Maria; MARCONI, Marina de Andrade. Fundamentos de metodologia científica. 5. ed. São Paulo: Atlas. 2010.

MARINKOVIC, N.; VITALE, K.; HOLCER, N. J.; DZAKULA, A.; PAVIC, T. Management of hazardous medical waste in Croatia. Waste Management, [S. I.], v. 28, n. 6, p. 1049-1056, 2008. 
MINISTÉRIO DO TRABALHO E EMPREGO. Portaria n. ${ }^{\circ}$ 485, de 11 de novembro de 2005. Aprova a Norma Regulamentadora n. 32 (Segurança e Saúde no Trabalho em Estabelecimentos de Saúde). Brasília, DF: Ministério do Trabalho e Emprego, 2005.

MORESCHI, C.; REMPEL, C.; BACKES, D. S.; CARRENO I.; SIQUEIRA, D. F.; MARINA, B. A importância dos resíduos de serviço de saúde para docentes, discentes e egressos da área da saúde. Revista Gaúcha de Enfermagem, [S. I.], v. 35, n. 2, p. 20-26, 2014.

NASCIMENTO, T. C.; JANUZZI, W. de A.; LEONEL, M.; SILVA, V. L.; DINIZ, C. G. Ocorrência de bactérias clinicamente relevantes nos resíduos de serviços de saúde em um aterro sanitário brasileiro e perfil de susceptibilidade a antimicrobianos. Revista da Sociedade Brasileira de Medicina Tropical, Uberaba, v. 42, n. 4, p. 415-419, jul./ago. 2009.

OLIVEIRA, L. L.; SOUZA, P. M.; CLEMENTINO, F. S.; PAIVA, S. C.; ROCHA, F. D. L. R. Resíduos dos serviços de saúde: desafios e perspectivas na atenção primária. Revista Enfermagem UERJ, Rio de Janeiro, v. 22, n. 1, p. 29-34, 2014.

PENATTI, Fabio Eduardo; GUIMARÃES, Solange T. Lima; SILVA, Paulo Marcos. Gerenciamento de resíduos químicos em laboratórios de análises e pesquisa: o desenvolvimento do sistema em laboratórios da área química. In: WORKSHOP INTERNACIONAL EM INDICADORES DE SUSTENTABILIDADE (WIPIS), 2., 2008, São Carlos. Anais [...]. São Carlos: USP, 2008. p. 106119.

SEVERO, E. A.; OLEA, P. M.; NODARI, C. H.; GUIMARÃES, J. C. F. de; DORION, E. Benefícios advindos do gerenciamento de resíduos de serviço de saúde na Serra Gaúcha (Brasil). Espacios, [S. I.], v. 33, n. 8, p. 12, 2012.

VENTURA, Katia Sakihama; REIS, Luisa Fernanda Ribeiro; TAKAYANAGUI, Angela Maria Magosso. Avaliação do gerenciamento de resíduos de serviços de saúde por meio de indicadores de desempenho. Engenharia Sanitária e Ambiental, [S. I.], v. 15, n. 2, p. 167176, 2010. 